\title{
Article
}

Mycosphere

\section{Comparison of antibacterial and antibiofilm activity properties of Hypogymnia tubulosa (Schaer.) Hav. lichen extracts from different locations in Turkey}

\author{
Özyiğitoğlu $G^{1}$, Açıkgöz B ${ }^{2}$, Tahiroğlu $G^{2}$ and Sesal NC ${ }^{1^{*}}$ \\ ${ }^{1}$ Marmara University, Faculty of Arts and Sciences, Biology Department, Istanbul, Turkey \\ ${ }^{2}$ Marmara University, Institute of Pure and Applied Sciences, Biology Department, Istanbul, Turkey
}

Özyiğitoğlu G, Açıkgöz B, Tahiroğlu G, Sesal NC 2017 - Comparison of antibacterial and antibiofilm activity properties of Hypogymnia tubulosa (Schaer.) Hav. lichen extracts from different locations in Turkey. Mycosphere 8(8), 994-1002, Doi 10.5943/mycosphere/8/8/2

\begin{abstract}
The levels of bioactivity in lichens can change in response to environmental stress. For this reason, it was decided to compare the activity levels of Hypogymnia tubulosa (Schaer.) Hav. (Parmeliaceae) samples collected from six different localities in Turkey and the factors that may be effective. We also questioned our opinion that antibacterial activity is not directly proportional to the effectiveness of the antibiotic. The in vitro antibacterial activity and antibiofilm effect of diethyl ether (DE) and chloroform-methanol-acetone (CMA) extracts of the lichen H. tubulosa were explored against two pathogenic microbial strains of Staphylococcus aureus-ATCC 25923 and Enterococcus faecalis-ATCC 29212. Antibacterial activity was screened by disk diffusion method through the minimal inhibitory concentration (MIC). Biofilm inhibitory potency of the extracts was measured by spectrophotometrically. Most of the tested extracts of $H$. tubulosa demonstrated inhibitory effects against $S$. aureus and E. faecalis as strong as antibiotics. Differences of the findings depending on locality, habitat and extract variables were evaluated. The most antibacterially active samples were from Bursa (Location 4 and 6), both DE and CMA extracts with MIC values of $100 \mu \mathrm{g} / \mathrm{ml}$, did not show inhibition effect against the bacterial biofilm. CMA extract of the Bolu sample (Location 3) with lower antibacterial effect, significantly reduced biofilm formation of both strains measured with lower absorbance levels compared to control groups. This result confirms that the samples with low antibacterial activity have more inhibitory effect on biofilm formation. In addition, different results were obtained according to localities among the samples of the same lichen species. Environmental factors influence the active substances produced by lichens. The results of this study present evidences of antibiofilm potential as well as strong antibacterial effect of $H$. tubulosa as promising source of antibacterial drugs.
\end{abstract}

Keywords - Hypogymnia tubulosa - antibacterial activity - MIC - antibiofilm activity

\section{Introduction}

Lichens consisting of a fungus partner and an eukaryotic alga and/or cyanobacterium as a photosynthetic partner are symbiotic organisms able to produce an impressive variety of unique secondary metabolites that are necessary to protect themselves during their growth and development (Le Pogam et al. 2015). A positive correlation was reported between metabolite concentrations in lichens and ecological factors through several papers reviewed by Kim et al. 
(2015a). Many environmental factors including light, UV exposure, elevation, season and temperature have been reported to have an impact on gene expressions involved in the production of lichen secondary metabolites (Deduke et al. 2012). Therefore, differences arising in the results of the same species may come from the influence of various ecological factors in different regions for instance geographic location and climatic variations, micro-habitat conditions, and the air quality affecting the amount of nitrogen and carbon required for the algal partner (Çobanoğlu Özyiğitoğlu 2016). A sufficient intensity of UV exposure is stated as the most significant factor that affects diversity of secondary compounds in lichens (Waring 2008). Particularly, phenolic compounds including depsides, depsidones, usnic acid and pulvinic acid derivatives have been stated as UVabsorbing compounds. Concentrations of these phenolic substances rise up with increased photosynthetic activity due to increased light and temperature (Kim et al. 2015a).

Recent studies on the bioactivity properties of many lichen species indicate that lichens are a valuable source of chemical compounds with pharmaceutical potential. Over the past decade, an increase in the research on antimicrobial (Rankovic et al. 2009, Mitrovic et al. 2011, Stojanovic et al. 2013), cytotoxic, antiproliferative and anticancer (Molnar \& Farkas 2010, Shrestha \& St. Clair 2013, Shukla et al. 2010) biological activities of lichens and lichen metabolites is quite remarkable (Kim et al. 2015b). In the "Catalogue of standardized chromatographic data and biosynthetic relationships for lichen substances" by Elix (2014), 854 compounds were described. Today, more than 1000 chemically identified lichen metabolites have been reported (Stocker-Wörgötter 2015). These substances can be used as natural antimicrobial agents, and are seen as candidates to become an alternative way to discover new drugs (Shukla et al. 2010). The strength of antimicrobial activity is controlled by several factors such as the species of lichen and test microorganism, the environmental conditions of collection site, the amount of extract and the type of solvent (Çobanoğlu Özyiğitoğlu 2016).

Since microorganisms continuously acquired drug resistance and vigorous biofilm formations, the need to develop new effective antimicrobial medicines has emerged. A biofilm is defined as a sessile microbial community characterised by cells that are attached to a substratum or to other cells and embedded in a protective matrix of extracellular polymeric substance made of exopolysaccharides, nucleic acids, and proteins which is a result of Quorum Sensing mechanism of bacteria (Dong et al. 2007, Archer et al. 2011). Biofilms are highly resistant to host defence mechanisms (Bendouah et al. 2006). Over the last decade, Gram positive commensal bacterial strains of Staphylococcus aureus and Enterococcus faecalis have arisen as serious pathogens that leading to biofilm-associated infections in human due to their biofilm formation and high resistance to many antibiotics (Otto 2008, Talebi et al. 2015). Antibiotics that are effective against bacteria do not usually mean biofilm inhibitors. Because these antibiotics that kill or cause stress in bacteria can induce bacteria to form more biofilm. It is better if it does not kill but interrupt communication between bacteria. Many plant-based substances such as 6-gingerol (Kim et al. 2015a), polyphenols in Rosa rugosa- Chinese rose (Zhang et al. 2014), flavanones in Combretum albiflorum- the Malagasy plant (Vandeputte et al. 2011), as well as zeaxanthin (Gökalsin et al. 2017), atranorin, fumarprotocetraric acid and usnic acid (Pompilio et al. 2013, Nithyanand et al. 2015, FernándezMoriano et al. 2017) in lichens have been reported as biofilm inhibitors and continue to be investigated.

Considering the need for new drugs, the present study evaluates the in vitro antibacterial activity and antibiofilm potential of the extracts of the epiphytic foliose lichen Hypogymnia tubulosa (Schaer.) Hav. collected from different geographic locations in Turkey. There have been previous studies on the antimicrobial activity of Hypogymnia species (Yilmaz et al. 2005, Rankovic et al. 2009, Cansaran-Duman et al. 2010, Stojanovic et al. 2013), however no reports on the antibiofilm activity. It is also intended to question the bioactivity results and the causes that vary according to the region where the lichen samples are collected. Therefore, this study is aimed to contribute to the pharmacological uses of lichens, and at the same time, provide the first data for the inhibitory effect of $H$. tubulosa against formation of bacterial biofilms. 


\section{Materials \& Methods}

\section{Lichen material}

The samples of lichen Hypogymnia tubulosa (Schaer.) Hav. were collected between 15/05/2014 to 24/08/2014 from fir trees (Abies bornmülleriana Mattf.) in Çanakkale, Balıkesir, Bolu and Bursa provinces in Turkey (Table 1). Collected samples were dried at room temperature before identification. Determination of the lichen species was accomplished by G. Özyiğitoğlu using standard methods (Smith et al. 2009). The voucher specimens were preserved in facilities of the Department of Biology, Faculty of Science and Arts at Marmara University.

Table 1 Locality information about $H$. tubulosa samples from 4 different cities in Turkey

\begin{tabular}{|c|c|c|c|c|}
\hline $\begin{array}{l}\text { Locality } \\
\text { no }\end{array}$ & Locality & Coordinates & $\begin{array}{l}\text { Altitude } \\
\text { (m) }\end{array}$ & $\begin{array}{l}\text { Collection } \\
\text { Date }\end{array}$ \\
\hline 1 & $\begin{array}{l}\text { Çanakkale, Ida Mountains } \\
\text { (Kazdağları), Ayazma, }\end{array}$ & $\begin{array}{l}\text { N39 } 41^{\prime} 36.3^{\prime \prime}- \\
\text { E26 } 52^{\prime} 16.5\end{array}$ & 1714 & 15.5.2014 \\
\hline 2 & $\begin{array}{l}\text { Balıkesir, İda Mountains } \\
\text { (Kazdağları), }\end{array}$ & $\begin{array}{l}\text { N 39॰38'29.3" -E } \\
26^{\circ} 55^{\prime} 16.1^{\prime \prime}\end{array}$ & 1500 & 16.5 .2014 \\
\hline 3 & $\begin{array}{l}\text { Bolu, Aladağlar Mountains, } \\
\text { Şerif Yüksel Research Forest }\end{array}$ & $\begin{array}{l}\mathrm{N} \quad 40^{\circ} 37^{\prime} 41^{\prime \prime}- \\
\mathrm{E} 25^{\circ} 34^{\prime} 23^{\prime \prime}\end{array}$ & 1590 & 18.5 .2014 \\
\hline 4 & $\begin{array}{l}\text { Bursa, Uludağ Mountain, } \\
\text { Kestel to Alaçam National } \\
\text { Park }\end{array}$ & $\begin{array}{l}\text { N4006'44.3"- } \\
\text { E29 } 17^{\circ} 27.6^{\prime \prime}\end{array}$ & 1168 & 22.8 .2014 \\
\hline 5 & $\begin{array}{l}\text { Bursa, Uludağ Mountain, } \\
\text { around the waterfall }\end{array}$ & $\begin{array}{l}\text { N400' } 48.4^{\prime \prime}- \\
\text { E29¹7' } 14.5^{\prime \prime}\end{array}$ & 1115 & 23.8.2014 \\
\hline 6 & $\begin{array}{l}\text { Bursa, Uluda } \breve{g} \text { Mountain, } \\
\text { Alaçam National Park }\end{array}$ & $\begin{array}{l}\text { N4006'01.6"- } \\
\text { E29 } 17^{\circ} 11.2^{\prime \prime}\end{array}$ & 1600 & 24.8.2014 \\
\hline
\end{tabular}

\section{Test microorganisms and media}

Staphylococcus aureus ATCC 25923 and Enterococcus faecalis ATCC 29212 were used as bacterial strains that were purchased from Yeditepe University (Istanbul). The solid cultures were stored at $4{ }^{\circ} \mathrm{C}$, incubated at $37{ }^{\circ} \mathrm{C}$ for 1 night after inoculating Luria-Bertani liquid medium for use in the experiment.

\section{Preparation of lichen extracts}

The identified lichen samples were cleaned from foreign materials such as soil, crustaceans, moss, etc. and washed. After dried, they were powdered with liquid nitrogen. The powdered lichen samples were weighed and taken in sterile glass bottles. Two solvents were used in the extraction process. The first solvent contains equal amounts of Chloroform-Methanol-Acetone (CMA) and the second solvent consists of Diethyl Ether (DE). The lichen samples were suspended in sterile containers for 2 nights in the solvents and the resulting solutions were filtered, then the solvents were evaporated in a rotary evaporator under vacuum. The obtained extracts were taken in sterile Eppendorf tubes and kept at $-20{ }^{\circ} \mathrm{C}$ until used after weighing. The extracts acquired from two solvents were tested separately.

\section{In vitro antibacterial assays}

Disk Diffusion Method: The bacterial suspensions adjusted to the $0.5 \mathrm{Mc}$ Farland standard were cultivated in Petri dishes with LB agar media. Each lichen extract which is sufficient for subsequent processing of lichen extracts is dissolved in the solvent used for extraction, centrifuged at 10,000 $\mathrm{rpm}$ for $10 \mathrm{~min}$, and then sterilized by filtration through $0.45 \mu \mathrm{m}$ pore diameter. Using Kirby-Bauer Disk diffusion method; $20 \mu \mathrm{l}$ of lichen extracts adjusted to $400 \mu \mathrm{g} / \mathrm{ml}$ were impregnated into sterile 
discs, placed on the surfaces of the bacteria-fed media and allowed to incubate for 1 night at $37^{\circ} \mathrm{C}$ in the incubator after 30 minutes at room temperature.

Antibiotic discs of Vancomycin (Oxoid) for bacterial strains were used as positive controls, and the two solvents methanol-acetone-chloroform (CMA) and diethyl ether (DE) were used as negative controls. For each extract, the experiments were repeated three times and the averages of the measurements were taken.

Minimal Inhibitory Concentration: Doses of lichen extracts which are effective according to the disc diffusion measurement results, adjusted to 100-10\% of the amount used in the disc diffusion, were added to LB medium containing bacterial suspensions adjusted to $0.5 \mathrm{McF}$ standard. The lowest dose of the extract that inhibited bacteria was considered MIC according to the results measured after 1-night incubation at $37{ }^{\circ} \mathrm{C}$. Antibiotic-Antimycotic solution (SIGMA-A5955) was used as a positive control in separately determined doses for each bacterium.

\section{Antibiofilm assay}

In experiments performed in 24-well sterile plates, overnight cultures of bacteria (OD: 625 nm, 0.5 Mc Farland) were diluted 1: 100 with LB broth medium. $2 \mathrm{ml}$ of diluted bacterial cultures were inoculated into plate wells and then lichen extracts were added at their sub-MIC concentrations to observe the effects on biofilm formation. As a control, tested bacteria and medium-containing group were used. The samples were allowed to incubate at $37^{\circ} \mathrm{C}$ for 4 days. On the $2^{\text {nd }}$ and $3^{\text {rd }}$ days, $500 \mu \mathrm{l}$ was removed from the samples at regular intervals and the total volume was kept constant by adding the extract-bacteria-medium again at the necessary ratios. On day 4, the wells were washed 3 times with sterile distilled water to remove planktonic bacterial cells which did not form the biofilm form in the environment. The samples were then treated with $0.01 \%$ basic fuchsine for 10 minutes to provide staining of the biofilm structure. The wells were washed again with sterile distilled water until the excess dye in the medium was removed. The stained cells were dissolved by adding 95\% ethanol to the wells and the mass of biofilm was measured at OD: $650 \mathrm{~nm}$ with $95 \%$ ethanol blinded.

\section{Statistical analysis}

All values were expressed as mean \pm SD calculated by Descriptive statistics. SPSS 20 statistics package was used for the analysis.

\section{Results}

\section{Antibacterial results}

In this study determined quantitative antimicrobial potentials of $H$. tubulosa which are collected from different locations of Turkey and dissolved in the different solvents. The results of disk diffusion assay and MIC values for DE and CMA extractions of $H$. tubulosa lichen are reported in Table 2. Except for CMA extracts of samples from Çanakkale, all tested extracts of $H$. tubulosa demonstrated inhibitory effects against $S$. aureus and E. faecalis. Most effective groups against $S$. aureus growth were determined from Bursa samples (Location 4 and 6), both DE and CMA extracts with MIC values of $100 \mu \mathrm{g} / \mathrm{ml}$, whereas against E. faecalis was sampled from Bolu (Location 3), DE extract with a MIC value of $400 \mu \mathrm{g} / \mathrm{ml}$. The antibacterial potential of both DE and CMA extracts of $H$. tubulosa was significantly higher in the samples from Bolu and Bursa (Location 3, 4, 5, 6 in the Table 2) than that of the applied positive control against $S$. aureus. The DE extracts of samples from Bolu (Location 3) and from Çanakkale (Location 1) showed inhibition on the growth of E. faecalis as strong as Vancomycin did.

\section{Antibiofilm results}

The first data for the inhibitory effect of $H$. tubulosa against formation of bacterial biofilms was recorded. The results for effects of the lichen extracts on biofilm formation of two bacteria 
were given in the Table 3. The best antibiofilm activity against S. aureus and E. faecalis was detected as CMA extract of samples from Bolu (Location 3) by comparing the measured absorbance (OD) levels with control groups. While CMA extracts of samples from Çanakkale did not show any effects on biofilm, DE extracts of this group reduced biofilm formation of the both strains. It was observed that both extracts of samples from Bursa (Location 4 and 6 caused an increase on biofilm formation of $S$. aureus. However, DE and CMA extracts of samples from Location 6 demonstrated significant antibiofilm activity against E. faecalis. Two extracts of samples from Bursa (Location 5 didn't show any antibiofilm activity against tested microorganisms.

Table 2 Antibacterial activities in the disk diffusion and minimum inhibitory concentrations (MIC) of $H$. tubulosa extracts

\begin{tabular}{|c|c|c|c|c|}
\hline \multirow{3}{*}{$\begin{array}{l}\text { H. tubulosa } \\
\text { Sample } \\
\text { Number }\end{array}$} & \multicolumn{4}{|c|}{ Growth Inhibition Zones $(\mathrm{cm}) /$ MIC Values $(\mu \mathrm{g} / \mathrm{ml})$} \\
\hline & S. aureus & & E. faecalis & \\
\hline & $\mathrm{DE}$ & CMA & $\mathrm{DE}$ & CMA \\
\hline $1 *$ & $1.3( \pm 0.04) / 400$ & $-/-$ & $1.5( \pm 0.04) / 400$ & $-/-$ \\
\hline $2 *$ & $1.7( \pm 0.08) / 400$ & $1.1( \pm 0.04) / 400$ & $1.3( \pm 0.04) / 400$ & $1.1( \pm 0.08) / 400$ \\
\hline $3 *$ & $1.9( \pm 0.04) / 400$ & $1.4( \pm 0.08) / 100$ & $1.8( \pm 0.08) / 400$ & $1.5( \pm 0.00) / 100$ \\
\hline $4 * *$ & $2.7( \pm 0.04) / 100$ & $2.6( \pm 0.08) / 100$ & $1.2( \pm 0.04) / 400$ & $1.3( \pm 0.08) / 400$ \\
\hline $5 * *$ & $2.3( \pm 0.08) / 200$ & $2.4( \pm 0.04) / 200$ & $1.5( \pm 0.04) / 200$ & $2.0( \pm 0.04) / 300$ \\
\hline $6^{* *}$ & $2.7( \pm 0.08) / 100$ & $2.6( \pm 0.04) / 100$ & $0.9( \pm 0.04) / 400$ & $1.0( \pm 0.04) / 400$ \\
\hline
\end{tabular}

DE: Diethyl Ether CMA: Methanol-Acetone-Chloroform Va: Vancomycin Solution: SIGMA A5955

-: Inactive

*: S. aureus Va: $1.5 \pm 0.02$ / Solution: 0.2; E. faecalis Va: $1.5 \pm 0.02$ / Solution: 20

**: S. aureus Va: 1.9 / Solution: 0.2; E. faecalis Va: 2.5 / Solution: 20

Table 3 Antibiofilm activities of $H$. tubulosa extracts against two bacteria.

\begin{tabular}{ccccc}
\hline $\begin{array}{c}\text { H. tubulosa } \\
\text { Sample } \\
\text { Number }\end{array}$ & DE & \multicolumn{3}{c}{ Measured Absorbance (OD) Levels } \\
E. faecalis \\
\hline $1^{*}$ & $0,055( \pm 0,007)$ & CMA & DE & CMA \\
$2^{*}$ & $0,069( \pm 0,0004)$ & $0,108( \pm 0,008)$ & $0,123( \pm 0,001)$ & $0,083( \pm 0,004)$ \\
$3^{*}$ & $0,050( \pm 0,001)$ & $0,036( \pm 0,06)$ & $0,088( \pm 0,02)$ & $0,038( \pm 0,002)$ \\
$4^{* *}$ & $0,5388( \pm 0,02)$ & $0,351( \pm 0,02)$ & $0,1177( \pm 0,02)$ & $0,0913( \pm 0,02)$ \\
$5^{* *}$ & - & - & - & - \\
$6^{* *}$ & $0,1220( \pm 0,02)$ & $0,1012( \pm 0,02)$ & $0,0892( \pm 0,02)$ & $0,0722( \pm 0,02)$ \\
\hline
\end{tabular}

*Control groups: S. aureus (OD: $650 \mathrm{~nm}): 0,057( \pm 0,002)$; E. faecalis (OD:650 nm): 0,068 $( \pm 0,002)$

**Control groups: S. aureus (OD: $650 \mathrm{~nm})$ : 0,063 ( $\pm 0,002)$; E. faecalis (OD:650 nm): 0,098 $( \pm 0,002)$

\section{Discussion}

The data obtained from the bioactivity assays of $H$. tubulosa in the present study were evaluated and discussed on three variables; the locality, the habitat and the extract (solvent and dose). Substrate was not one of the variables because sampling was done over the same species of fir trees at all locations. In addition, the correlation between the antibiotic and antibiofilm efficacy of the extracts was also examined.

When the results were determined by rating in the antibacterial and the antibiofilm activity of $H$. tubulosa in terms of the locality, differences demonstrated that environmental factors influence 
the active substances in the lichen extracts. Namely, the antibacterial activity of lichen specimens collected from the Bursa (Location 4, 5,6) locality with a higher effect against $S$. aureus differs from other regions. Again, Bolu (Location 3) lichen samples were more active against both $S$. aureus and E. faecalis. The activity of both antibacterial and antibiofilm was found to be low in the Balıkesir (Location 2) lichen samples. There are no large differences in altitude and they are all forested areas. However, Bursa and Bolu localities have a colder and continental climate while Balikesir locality is more moderate and windy. The rainfall and the periods of snow fall are different. Therefore, it is thought that these results are different due to climate conditions as well as altering levels of light. No clear information is available about air quality level of the localities.

Differences in the bioactivity of the same lichen species collected from different geographic locations can be originated from variety and number of secondary metabolites produced due to different habitat and micro-habitat conditions. Molnar \& Farkas (2011) detected no significant genetic differentiation between the secondary metabolites of the $H$. physodes and its genetic variability through geographic distributions. However, Deduke et al. (2012) revealed environmental factors such as sun exposure, humidity, mineral deposits etc. act on genes that are effective in the production of lichen secondary metabolites. Furthermore, air pollution and heavy metal accumulation may also affect physiology of particularly the algal partner (Deduke et al. 2012, Çobanoğlu Özyiğitoğlu 2016). Hauck et al. (2013) reported that the amount of lichen substances in the epiphytic lichen Hypogymnia physodes increased with increasing heavy metal concentration in the substratum.

Solvent difference is another factor increases the resolution of different active ingredients in lichen extracts. In this case, it can be effective in changing the bioactivity. Main constituents of $H$. tubulosa are physodalic acid, physodic acid, 3-hydroxy physodic acid and atranorin in the literature (Huneck \& Yoshimura 1996, Orange et al. 2001, Romagni \& Dayan 2002, McCune 2002). Most of the antimicrobial studies on $H$. tubulosa have been carried out with crude extracts not the secondary compounds. Only Yilmaz et al. (2005) evaluated 3-hydroxyphysodic acid constituent besides the extracts. The diethyl ether extract of $H$. tubulosa and also the 3-hydroxyphysodic acid were reported showing the best antimicrobial activity compared to acetone, chloroform petroleum ether, ethanol against various microorganisms including $S$. aureus respectively. In the present study, similarly not also DE extracts of $H$. tubulosa showed high antibacterial activity against $S$. aureus, but also CMA extracts. In terms of solvents, DE extracts of samples from Çanakkale, Balıkesir and Bolu (Location 1, 2 and 3) acted more effective antibacterially against both bacteria, on the other hand both DE and CMA extracts from Bursa (Location 4, 5,6) were very active against $S$. aureus. On the other hand, Cansaran-Duman et al. (2010) reported no remarkable antibacterial activity of $H$. tubulosa acetone extract against $S$. aureus and E. faecalis, unlike the results of the present study. From Çanakkale locality (Location 1), while only DE extracts showed low or same levelled antibacterial effects with the control, their antibiofilm activities were stronger. This results is the first report for the antibiofilm activity of specifically $H$. tubulosa, no study has been reported before. However, lichen secondary metabolites have been evaluated in terms of their capability of inhibition bacterial biofilm in recent studies. Pompilio et al. (2013) tested usnic acid and atranorin against methicillin-resistant Staphylococcus aureus, and found them able to affect adhesion and biofilm formation of cystic fibrosis $S$. aureus strains. In the present study, H. tubulosa extracts exhibited inhibitory potential against $S$. aureus and E. faecalis biofilms, probably due to its atranorin or usnic acid content. The data by Cansaran-Duman et al. (2010), notified that $H$. tubulosa contains a high amount of usnic acid in the acetone extract supported our outcome.

Furthermore, Cansaran-Duman et al. (2010) determined the crude extracts of H. vittata, H. physodes and $H$. tubulosa for antimicrobial activity against 7 bacteria, and their results showed that the maximum antimicrobial activity was in $H$. tubulosa acetone extract containing the highest amount of usnic acid, against $B$. subtilis within tested Gram positive bacteria and E. coli from Gram negatives. Besides, Stojanovic et al. (2013) found that methanol extract of $H$. physodes exhibit not very remarkable inhibition on the bacteria including $S$. aureus growth compared to the control antibiotics. According to the study by Rankovic et al. (2009), acetone and methanol extracts of $H$. 
physodes strongly inhibited the growth of all tested Gram-positive and Gram-negative bacteria including S. aureus. Also, Mitrovic et al. (2011) reported high antimicrobial activity for the methanol extract of $H$. physodes besides its antioxidative and antiproliferative potential. The differences in the results of these studies for the same lichen species are not solvent-dependent, most likely depend on other factors such as geographical location, climate changes, microhabitat conditions and air quality influencing extracted lichen samples.

The antibiotic effect of the extract is not directly proportional to its biofilm inhibition effect against the same bacterial strain. While antibacterial activity of Bolu specimens was not high, the efficiency of antibiofilm was high. It does not kill, but it interrupts communication between bacteria. The low antibiofilm effect of the samples with high antibacterial effect in the localities in Bursa may be due to the increase in the biofilm formation rate of the bacteria as the bacteria enter into the death stress. As a conclusion, those extracts with lower antibacterial activity than the control antibiotic indicated higher effects against biofilm formation.

\section{Conclusion}

In conclusion, results of this study show that DE and CMA extracts of lichen H. tubulosa provide significant antibacterial and antibiofilm activity against the both Gram-positive bacteria at varying levels depending on the locality. It is strongly probable that climatic and habitat factors influence the active substances in the lichen extracts. The antibacterial results were not clearly solvent-dependent, but rather they changed dependent on the geographic positions.

The antibiotic effect of the extracts was found not to be directly proportional to the antibiofilm effect. The biofilm inhibitory power of $H$. tubulosa extracts come from presumably due to its atranorin content. But, more research is required for the detection of active substances in lichen extracts. It is concluded those extracts with low antibacterial activity showed high inhibition effects on biofilm formation.

There is a need to further investigate what the biofilm inhibitors are in the lichen extracts and whether these substances or extracts show the same effect, at the same time factors that increase the production of lichen secondary metabolites. These results suggest that lichens may be an important potential source of antibiotic drugs.

\section{Acknowledgements}

We would like to thank the Marmara University Research Fund for supporting this research with the project numbered FEN-B-120514-0154. We also thank İskender Karaltı, Barış Gökalsın and Ezgi Uçarkuş for contributions in the laboratory studies and participations in the field.

\section{References}

Archer NK, Mazaitis MJ, Costerton JW, Leid JG et al. 2011 - Staphylococcus aureus biofilms. Properties, regulation and roles in human disease. Virulence 2, 445-459.

Bendouah Z, Barbeau J, Hamad WA, Desrosiers M. 2006 - Biofilm formation by Staphylococcus aureus and Pseudomonas aeruginosa is associated with an unfavorable evolution after surgery for chronic sinusitis and nasal polyposis. Otolaryngology-Head and Neck Surgery 134, 991-996.

Cansaran-Duman D, Cetin D, Simsek H, Coplu N. 2010 - Antimicrobial activities of the lichens Hypogymnia vittata, Hypogymnia physodes and Hypogymnia tubulosa and HPLC analysis of their usnic acid content. Asian Journal of Chemistry 22, 6125-6132.

Çobanoğlu Özyiğitoğlu G, Açıkgöz B, Sesal C. 2016 - Lichen secondary metabolites: Synthesis pathways and biological activities. Acta Biologica Turcica 29, 150-163.

Deduke C, Timsina B, Piercey-Normore MD. 2012 - Effect of environmental change on secondary metabolite production in lichen-forming fungi. In: Young S., (Ed.) International Perspectives on Global Environmental Change: 197 - 230. InTech.

Dong YH, Wang LH, Zhang LH. 2007 - Quorum-quenching microbial infections: mechanisms and implications. Philosophical Transactions of the Royal Society B, 362, 1201-1211. 
Elix JA. 2014 - A Catalogue of Standardized Chromatographic Data and Biosynthetic Relationships for Lichen Substances. Third Edition. Published by the author, Canberra.

Fernández-Moriano C, Divakar PK, Crespo A, Gómez-Serranillos MP. 2017 - In vitro neuroprotective potential of lichen metabolite fumarprotocetraric acid via intracellular redox modulation. Toxicology and Applied Pharmacology 316, 83-94.

Gökalsın B, Aksoydan B, Erman B, Sesal NC. 2017 - Reducing virulence and biofilm of Pseudomonas aeroginosa by potential quorum sensing inhibitor carotenoid: zeaxanthin. Microbial Ecology DOI 10.1007/s00248-017-0949-3.

Hauck M, Boning J, Jacob M, Dittrich S et al. 2013 - Lichen substance concentrations in the lichen Hypogymnia physodes are correlated with heavy metal concentrations in the substratum. Environmental and Experimental Botany 85, 58-63.

Huneck S, Yoshimura I. 1996 - Identification of lichen substances. Springer, Berlin.

Kim HS, Lee SH, Byun Y, Park HD. 2015a - 6-Gingerol reduces Pseudomonas aeruginosa biofilm formation and virulence via quorum sensing inhibition. Scientific Reports 5, 8656; DOI:10.1038/srep08656

Kim H, Kim KK, Hur JS. 2015b - Anticancer activity of lichen metabolites and their mechanisms at the molecular level. In: Recent Advances in Lichenology- Modern Methods and Approaches in Lichen Systematics and Culture Techniques, Volume 2 (Eds. Upreti DK, Divakar PK, Shukla V, Bajpai R.) 201 - 208. Springer, India. DOI 10.1007/978-81-3222235-4_11

Le Pogam P, Herbette G, Boustie J. 2015 - Analysis of lichen metabolites, a variety of approaches. In: Upreti DK, Divakar PK, Shukla V , Bajpai R. (eds.) Recent Advances in Lichenology Modern Methods and Approaches in Biomonitoring and Bioprospection 1, 229-261. Springer, India. DOI 10.1007/978-81-322-2235-4_11

McCune B. 2002 - Hypogymnia, In: T. H. Nash III, B. D. Ryan, C. Gries, F. Bungartz (eds.) Lichen Flora of the Greater Sonoran Desert Region 1, 228-238.

Mitrovic T, Stamenkovic S, Cvetkovic V, Tosic S et al. 2011 - Antioxidant, antimicrobial and antiproliferative activities of five lichen species. International Journal of Molecular Sciences $12,5428-5448$.

Molnar K, Farkas E. 2010 - Current results on biological activities of lichen secondary metabolites: a review. Zeitschrift fur Naturforschung C 65,157-173.

Molnar K, Farkas E. 2011 - Depsides and depsidones in populations of the lichen Hypogymnia physodes and its genetic diversity. Annales Botanici Fennici 48, 473-482.

Nithyanand P, Shafreen RMB, Muthamil S, Pandian SK. 2015 - Usnic acid, a lichen secondary metabolite inhibits Group A Streptococcus biofilms. Antonie van Leeuwenhoek 107, $263-$ 272.

Orange A, James PW, White FJ. 2001 - Microchemical Methods for the Identification of Lichens. British Lichen Society, London.

Otto M. 2008 - Staphylococcal Biofilms. Current Topics in Microbiology and Immunology 322, 207-228.

Pompilio A, Pomponio S, Di Vincenzo V, Crocetta V et al. 2013 - Antimicrobial and antibiofilm activity of secondary metabolites of lichens against methicillin-resistant Staphylococcus aureus strains from cystic fibrosis patients. Future Microbiology 8, 281-292.

Rankovic B, Misic M, Sukdolak S. 2009 - Antimicrobial activity of extracts of the lichens Cladonia furcata, Parmelia caperata, Parmelia pertusa, Hypogymnia physodes and Umbilicaria polyphylla. Biologia 64, 53-58.

Romagni JG, Dayan FE. 2002 - Structural diversity of lichen metabolites and their potential use. In: R.J. Upadhyay (eds.), Advances in Microbial Toxin Research and Its Biotechnological Exploitation: 151 - 169. Kluwer Academic / Plenum Publishers, New York

Shrestha G, St. Clair LL. 2013 - Lichens: a promising source of antibiotic and anticancer drugs. DOI 10.1007/s11101-013-9283-7 
Shukla V, Joshi GP, Rawat MSM. 2010 - Lichens as a potential natural source of bioactive compounds: a review. Phytochemistry Reviews 9, 303-314.

Smith CW, Aptroot A, Coppins BJ, Fletcher A et al. 2009 - The lichens of Great Britain and Ireland. The British Lichen Society, London, UK.

Stocker-Wörgötter E. 2015 - Biochemical diversity and ecology of lichen-forming fungi: Lichen substances, chemosyndromic variation and origin of polyketide-type metabolites (biosynthetic pathways). In: Upreti DK, Divakar PK, Shukla V and Bajpai R.(eds) Recent Advances in Lichenology- Modern Methods and Approaches in Lichen Systematics and Culture Techniques 2,161 - 179. Springer, India. DOI 10.1007/978-81-322-2181-4-11

Stojanovic I, Radulovic N, Cvetkovic V, Mitrovic T, Stamenkovic S. 2013 - Antimicrobial activity of methanol extracts of four parmeliaceae lichen species. Facta Universitatis Series: Physics, Chemistry and Technology 11, 45-53.

Talebi M, Moghadam NA, Mamooii Z, Enayati M et al. 2015 - Antibiotic resistance and biofilm formation of Enterococcus faecalis in patient and environmental samples. Jundishapur Journal of Microbiology 8, e23349.

Vandeputte OM, Kiendrebeogo M, Rasamiravaka T, Stevigny C et al. 2011 - The flavanone naringenin reduces the production of QS-controlled virulence factors in P. aeruginosa PAO1. Microbiology 157, 2120 - 2132. DOI 10.1099/mic.0.049338-0

Waring B. 2008 - Light exposure affects secondary compound diversity in lichen communities in monteverde, Costa Rica. Penn Science 6, 11-13.

Yilmaz M, Tay T, Kivanc M, Turk H, Turk AO. 2005 - The antimicrobial activity of extracts of the lichen Hypogymnia tubulosa and its 3-hydroxyphysodic acid constituent. Zeitschrift fur Naturforschung C: Journal of Biosciences 60, $35-38$.

Zhang J, Rui X, Wang L, Guan Y et al. 2014 - Polyphenolic extract from Rosa rugosa tea inhibits bacterial quorum sensing and biofilm formation. Food Control 42, 125-131. 